\section{Digitally take control of your surgery}

First there was Siri, then Hive, and more recently Amazon Alexa. The digital age certainly is pervading your home life so it is perhaps not surprising that you can digitally take control of your surgery too. Tyscor Pulse, from Dürr Dental, ingeniously shows you the performance of your suction and compressor systems and is compatible with almost all Dürr suction and compressors units including the popular VSA 300s. Things such as current

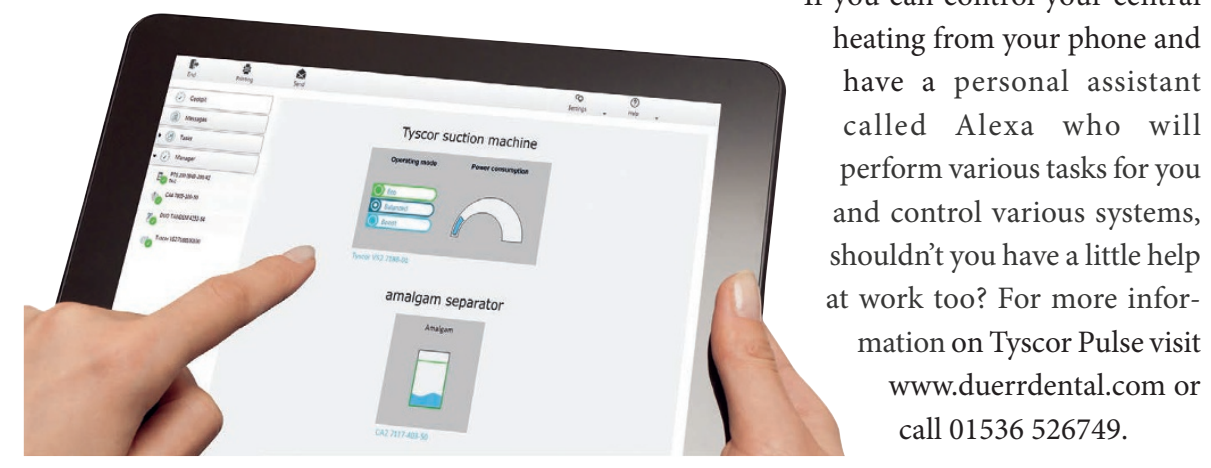

\section{Focusing on the keystones of modern dentistry}

Now an established part of the dental education calendar, Ivoclar Vivadent's ICDE event is back for 2017, bigger and better than ever. Following on from the sell-out successes of 2010 to 2015, this year's ICDE focus is three keystones of modern dentistry: 'Digital, Aesthetics and Efficiency'.

This highly popular two-day event, which takes place on 16-17 June, will bring together world-renowned dental professionals to present a wide range of opinions and case studies exploring the constantly evolving dental landscape. The 2017 confirmed speaker line-up includes Drs Attiq Rahman, Nilesh Parmar, Lida Swann and James Russell from a clinician's perspective, and Lee Culp, Carl Fenwick, Ian Smith, Petr Mysicka and

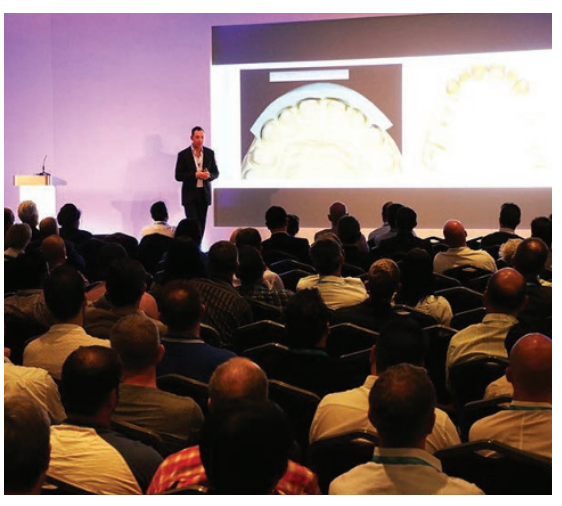

status, faults or maintenance messages, for example a prompt to change the filter, are immediately displayed on the monitor.

With Tyscor Pulse your practice equipment supply is always in view and can be accessed by engineers as well by you. The software will warn you if there is a malfunction, and will indicate whether the problem is something that can easily be rectified by a staff member or whether a service technician should be called. If you can control your central heating from your phone and have a personal assistant called Alexa who will perform various tasks for you work too? For mo ation on Tyscor Pulse visit www.duerrdental.com or \section{technical element of the event.}

Vicken Hatsakordzian representing the

This is the fifth ICDE event in the UK, and for the first time is being held in the centre of Leicester at two iconic venues. The daytime events will be held at the spectacular Curve Theatre situated in the city centre's vibrant Dr Milad Shadrooh, now better known as 'The Singing Dentist'. Successfully combining lectures with Q\&A sessions over the two days, there will also be a marketplace event with live demonstrations and opportunities to see the products featured in action.

As always, ICDE also promises an eventful evening on Friday 16 June, as delegates are invited to take part in a special event at The King Power Stadium, home of Leicester City Football Club. With access to the Keith Weller Suite, this promises to be an enjoyable evening featuring a gala dinner and live entertainment.

Tickets for both days of ICDE2017, including lunch and evening entertainment, start from $£ 250$ + VAT, with multiple hotel options available. Attending the event will also qualify for eight hours of verifiable CPD. Bookings can be made directly via icde.uk, or by calling 0116 284 7880. Places are strictly limited so book your place today to avoid disappointment. Cultural Quarter, and will be hosted by

\section{A new movement in} orthodontics is launched

New for 2017, Henry Schein Dental is delighted to announce the launch in the UK of Henry Schein Orthodontics, providing everything you need to run a successful orthodontic practice.

The new service offers an extensive range of orthodontic products from renowned manufacturers, including bracket systems, buccal tubes, molar bands, archwires and intraoral appliances. In addition, exclusive lines such as the innovative Carrière SLX self-ligating bracket and Carrière Motion Appliance, which limits extractions and turns complex Class II and Class III cases into simpler Class I cases, will also be available.

Henry Schein Orthodontics will stage a series of educational courses featuring luminaries of the orthodontic world including Dr Luis Carrière, who will deliver a Carrière Philosophy course on Innovative Concepts in the Correction of Class II and Class III Malocclusions. Courses are running throughout 2017 at Henry Schein Dental's training facilities and details are available at hsdeducation. co.uk.

To find out more about Henry Schein Orthodontics, request a product catalogue or arrange a visit from one of Henry Schein Dental's orthodontic product specialists visit hsdorthodontics.co.uk or speak to one of the orthodontic team on 01634266060.

All purchases of orthodontic equipment and materials will qualify for Rewards loyalty points. New members can sign up for Rewards today for free at hsdrewards.co.uk and automatically receive an additional 1,000 free bonus points. henryschein.co.uk

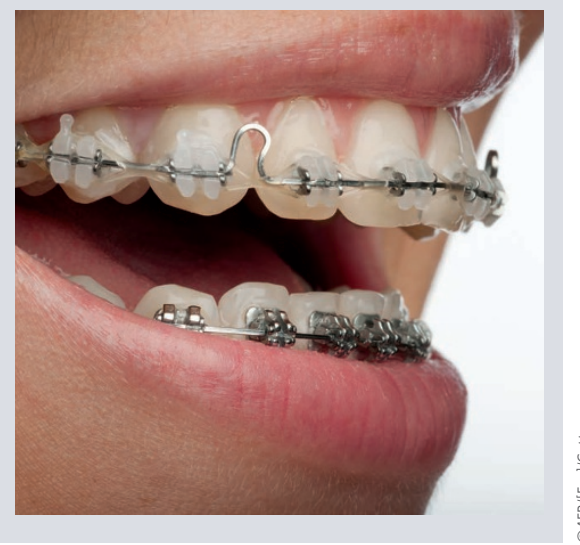

